This is an author produced version of a paper published in The Annals of Thoracic Surgery. This paper has been peer-reviewed but does not include the final publisher proof-corrections or journal pagination.

Citation for the published paper:

Brondén, Bjorn and Dencker, Magnus and Allers, Mats and Plaza, Ignacio and Jonsson, Henrik

"Differential distribution of lipid microemboli after cardiac surgery."

Ann Thorac Surg. 2006 Feb;81(2):643-8.

http://dx.doi.org/10.1016/j.athoracsur.2005.08.006.

Access to the published version may require journal subscription.

Published with permission from: Elsevier 


\section{Differential distribution of lipid micro-emboli after cardiac surgery}

Brondén B, M.D, ${ }^{1}$ Dencker M, M.D. ${ }^{2}$, Allers M, M.Sc. ${ }^{3}$, Plaza I. M.D. ${ }^{3}$,

Jönsson H, M.D.Ph.D. ${ }^{3}$

${ }^{1}$ Department of Thoracic Anesthesiology, Center for Heart and Lung Disease, Lund University Hospital, Lund, Sweden

${ }^{2}$ Department of Clinical Physiology, University Hospital Malmö, Malmö, Sweden

${ }^{3}$ Department of Cardiothoracic Surgery, Center for Heart and Lung Disease, Lund University

Hospital, Lund, Sweden

Corresponding author:

Henrik Jönsson, M.D., Ph.D.

Department of Cardiothoracic Surgery

Lund University Hospital

SE-221 85 Lund

Sweden

Tel +46 (46) 171000

Fax +46 (46) 158635

E-mail: henrik.jonsson@thorax.lu.se

Keywords: Lipid micro-emboli, Distribution, Porcine, Radioactive, Renal, Cerebral 


\begin{abstract}
Background:

Lipid micro-emboli (LME) found in shed blood during cardiac surgery have been shown to block capillaries of the brain postoperatively. In this study, the distribution of LME in different regions of the brain and other organs was examined. A novel porcine model using radioactive lipid particles was used.
\end{abstract}

\title{
Method:
}

Ten animals (two controls and eight cases), were anesthetized and put on CPB (cardiopulmonary bypass). A shed-blood phantom was produced from arterial blood, saline and tritium-labeled triolein. The phantom was infused into the CPB circuit. Tissue samples were taken post mortem from examined organs and prepared for scintillation counting. Levels of radioactivity were used as a measure of the uptake of lipid material.

\section{Results:}

High levels of radioactivity were found in kidney and spleen (5-10 times higher than in the other organs investigated). In the brain, radioactivity was found in all regions examined, and the gray matter showed the highest level of the regions examined.

\section{Discussion:}

This study shows that embolization of lipids is not a phenomenon restricted to the brain, but affected all the organs examined. The high levels found in the kidneys, and the relatively high levels in the gray matter of the brain further legitimize the discussion on the impact LME has on post-operative kidney and cognitive dysfunction. 


\section{Introduction}

The practice of retransfusing shed blood during cardiac surgery with cardiopulmonary bypass (CPB) using cardiotomy suction has been shown to be a major source of lipid micro-emboli (LME) (1-4). These lipid emboli have been shown to form small thrombi in the vasculature, and histological examination of brain after cardiac surgery has demonstrated lipid deposits in the capillaries in this organ (4). These phenomenon found in the capillary bed is sometimes referred to as small capillary arteriolar dilatations (SCADS) (4). In addition, SCADS/LME have been proposed as an important contributor to the postoperative cognitive dysfunction observed in some patients after surgery involving CPB (5;6).

Until now, attention has been focused on emboli in the brain and the effects they may have on cerebral function. In this study we wanted to investigate whether LME also affect other organs, and if so, the distribution of embolic load different organs. To achieve this, a novel porcine model employing radioactive LME was used. 


\section{Methods}

After gaining approval from the regional animal study ethics committee, ten adult landbred pigs (weight 66-72 kg) were used. Two animals were used as controls and eight animals formed a case group. During the experiment vital parameters, i.e. blood pressure, central venous pressure, pulse, nasopharyngeal temperature, ventilator settings and pulse oximetry were monitored continuously. Catheters for monitoring drug delivery and blood sampling were inserted into a vein in one of the ears, the jugular internal vein, and the femoral and carotid arteries.

\section{Anesthesia and perfusion}

Premedication was performed with an intramuscular injection of $15 \mathrm{mg} / \mathrm{kg}$ ketamine chloride (Ketalar ${ }^{\circledR}$, Pfizer Inc., New York, NY, USA) and 0.2 mg/kg xylasine (Rompun ${ }^{\circledR}$, Bayer, Gothenburg, Sweden). Anesthesia was induced by an intravenous injection of sodium thiopental (Pentothal ${ }^{\circ}$, Abbot, North Chicago, IL, USA) $10 \mathrm{mg} / \mathrm{kg}$ and Atropine ${ }^{\circledR}$ (Kabi Pharmacia, Uppsala, Sweden) $0.02 \mathrm{mg} / \mathrm{kg}$ were used. Surgical preparations were made for tracheotomy. After giving an intravenous injection of succinylcholine (Celocurin $®$, Ipex, Sweden) $0.2 \mathrm{mg} / \mathrm{kg}$ to obtain muscle relaxation, the endotracheal tube was inserted. Prior to Celocurinadministration a small intravenous dose of atracuriumbesylate (Tracrium®); Glaxo, Täby, Sweden) $0.2 \mathrm{mg} / \mathrm{kg}$ could sometimes be given to avoid muscle contractions. Anesthesia was maintained by infusion of $0.15 \mathrm{mg} / \mathrm{kg} / \mathrm{min}$ ketamine chloride and $0.01 \mathrm{mg} / \mathrm{kg} / \mathrm{min}$ pancuronombromide (Pavulon ${ }^{\circledR}$, N.V. Organon, Oss, the Netherlands), or by infusion of 0.1$0.2 \mathrm{mg} / \mathrm{kg} / \mathrm{min}$ propofol (Diprivan®, Astra-Zeneca, Sweden) together with intermittent injections of fentanyl (Leptanal®, Lilly, France) and atracuriumbesylate. 
The animals were connected to a ventilator and the $\mathrm{pCO}_{2}$ was maintained at between 4.5 and $6.0 \mathrm{kPa}$.

A sternotomy was performed to expose the heart, and the right atrium and the ascending aorta were cannulated after a full dose of heparin (LEO Pharma A/S, Copenhagen, Denmark) had been administered. A Jostra HL 15 heart-lung machine (Jostra AB, Lund, Sweden) was used with a Jostra Quadrox oxygenator and Jostra Quart arterial filter. Perfusion was maintained at approximately $2.0 \mathrm{l} / \mathrm{m}^{2} / \mathrm{min}$. Cardiopulmonary bypass was instituted as soon as the system was set up and the animal's circulatory stable. All animals underwent standardized perfusion for 40 minutes, and were then weaned from bypass.

\section{Administration of radiolabeled triolein}

A solution of radioactive triolein was prepared by mixing a $65 \%$ non-radioactive triolein solution (Carl Roth GmbH, Karlsruhe, Germany) with radioactive tritium-labeled triolein (Amersham BioSciences, Buckinghamshire, UK). The proportions used were such that $5 \mathrm{ml}$ of the final solution should contain $1 \mathrm{mCi}$ of radioactivity.

A shed blood phantom was made by mixing $200 \mathrm{ml}$ blood from the cardiotomy reservoir with $200 \mathrm{ml}$ saline and $5 \mathrm{ml}$ radioactive triolein solution. The shed blood phantom was gently agitated for approximately one minute and retransfused into the cardiotomy reservoir of the heart-lung machine after 20 minutes of bypass. It was allowed to flow into the reservoir as quickly as possibly, normally 30-60 seconds. After weaning from ECC, the animals were sacrificed using potassium chloride (Kaliumklorid, B. Braun, Melsungen, Germany) and sodium thiopental. 


\section{Sample preparation}

After termination, tissue samples were taken from the white matter of the brain, gray matter of the brain, brainstem, hippocampus, cerebellum, heart, lung, liver, cortex of the kidney, spleen, small intestine and skeletal muscle. Four tissue samples of 100-200 mg were dissected from each investigated organ.

To each sample $2 \mathrm{ml}$ Soulene 350® (Packard Bioscience, Groningen, the Netherlands) was added. The samples were placed in an air heater at $37^{\circ} \mathrm{C}$ for $24 \mathrm{~h}$. When the tissue samples had dissolved, $0.2 \mathrm{ml}$ hydrogen peroxide was added to decolorize the samples and they were then placed in the air heater at $60{ }^{\circ} \mathrm{C}$ for $30 \mathrm{~min}$. An additional $0.2 \mathrm{ml}$ hydrogen peroxide was added. Fifteen ml of scintillation fluid (Hionic Fluor, Packard Bioscience, Groningen, the Netherlands) was added, and the samples were then left to stand for 4-6 days in order to allow the chemoluminescence to decrease(7).

The level of radioactivity was measured by scintillation counting, using a liquid scintillation counter (14814 Win Spectral Guardian, Wallac Oy, Turku, Finland) together with the software supplied by the manufacturer (Easycount). This software automatically excludes background radiation(7). The specific activity of tritium was calculated for each sample. Two separate measurements were performed, and the mean value of the two measurements was used. Radioactivity is reported as the number of disintegrations per minute (DPM) per g (DPM/g).

\section{Statistics}

For each organ, a mean value was determined from the four specimens and the two radioactivity measurements. Values for the control animals and the case group were expressed as mean \pm 1 standard deviation, unless otherwise stated. In addition, the radioactivity in each 
animal was standardized by representing the amount of radioactivity found in each animal as a percentage of the total radioactivity (sum of all examined organs).

To compare differences in radioactivity within different regions of the brain, a repeated measurement ANOVA analysis was performed. A p-value $<0.05$ was considered significant. 


\section{Results}

No beta radiation was detected in the tissues of the control animals (Table 1). In the case group, beta radiation was detected in all tissues examined indicating the presence of LME. The highest levels of radioactivity were found in samples taken from the kidneys and spleen. The radioactivity in these organs was approximately 5-10 times higher than in the other organs examined (Table 1). Liver and the gray matter of the brain showed the third and fourth highest levels of beta radiation, respectively. The lowest levels were found in skeletal muscle (Table 1).

A high variation in radioactivity from animal to animal was found. However, the relative variation, between the organs in the animals was low (Figure 1). For example, kidney and spleen were the organs showing the highest level of beta radiation in each animal, and skeletal muscle was always found to have the lowest level of beta radiation.

The distribution of beta radiation in the regions of the brain examined showed differences which were statistically significant when tested with ANOVA analysis (Table 1). The level of radioactivity found in gray matter was significantly higher than in the other regions of the brain examined (t-test, $\mathrm{p}<0.05$ in all tests). Brainstem showed the lowest level of beta radiation in the brain. 


\section{Discussion}

This study shows that lipid-micro emboli introduced into the cardiopulmonary circuit, not only affects the brain, but is a global phenomenon affecting all organs. In addition, the variation from organ to organ is large where the kidneys, liver and spleen seeming to have the highest embolic load.

The kidneys were found to be the organ with the highest uptake of LME. Since the kidneys are well perfused organs (8), it is to be expected that they would receive a relatively large load of LME. However, the extremely high levels found in this study are surprising. In a recent study by Boston et al., blood flow to different organs was studied in a porcine model. In their study which also was performed at normothermia and with the same CPB flow, they found a higher blood flow to the brain than to the kidneys. In our study, we found nearly a 10 -fold higher beta radiation level in the kidneys than in the brain. This indicates that it is not only the blood flow to the kidneys that is responsible for the uptake of LME. In the model employed by Boston et al. fluorescent microspheres were used which is a validated method for measuring blood flow, whereas in our model we used lipid emboli, which are heterogeneous in size $(9 ; 10)$. As with the lipid emboli found in shed human blood, little is known about the distribution in size. However, in the cardiopulmonary circuit, the 40 micron arterial filter will probably break down larger emboli to a size less than 40 microns. It is therefore likely that other factors, such as the morphology of the capillary network may play a role, and the double capillary network (glomeruli and tubuli) found in the kidneys may be especially susceptible to lipid-micro emboli. 
A well-known complication after cardiac surgery is renal dysfunction (11). Since this study clearly shows that the kidneys have the greatest uptake of LME, a pertinent question is whether LME are a contributing factor to this complication. At least two different potential mechanisms organ dysfunction by lipid emboli are possible. Mechanical obstruction is of course one of them. It has been shown in vitro that mediastinal fat clogs filters and impairs circulation (12). This study shows a high uptake of lipid material in the kidneys, and it is therefore likely that these emboli cause a mechanical obstruction to blood flow. Another explanation could be a toxic reaction. It has been shown that oleic acid, when given intravenously to test animals, causes lung injury with edema and severe hypoxemia (13). In addition, it has been shown that uncharged fat (such as triglycerides) and also free fatty acids have toxic properties. In a feline model, triolein and oleic acid cause both vasogenic and cytotoxic cerebral edema when infused into the carotid artery (14). In this study, the charged oleic acid caused the greatest damage. This implies that lipid material can not only cause mechanical obstruction but chemical interactions may also play a negative role in the capillaries of the organs.

In conclusion, the finding of a high uptake of LME in the kidneys together with the wellknown problem of a postoperative renal dysfunction is intriguing. However, this study does not address the pathological effects of lipid-micro embolism on the kidneys. Therefore, further studies must be undertaken in this area.

The spleen and the liver had the second and third highest uptakes of LME. Both organs are well-perfused (8) and therefore expected to receive a high load of LME. Also, the spleen and the liver share the same type of capillary bed, the sinusoidal capillary (F Braet et al.). This capillary type is complex with apertures communicating with the underlying tissue. This 
morphological trait may play a role in trapping LME. In addition, the liver and the spleen are part of the reticuloendothelial system (ref med RES) and contain cells with phagocytic activity, which could actively take up LME. Although a high uptake was found in these organs, the clinical relevance is unclear.

The brain has been the organ of focus in previous research on LME/SCADS (2;4), and we therefore expected to find radioactive lipid material in our model, which was, indeed, the case. At first glance, the overall levels of beta radiation in the brain are lower than anticipated. Compared to kidneys and spleen for example, the levels are only a fraction of these levels, and could therefore be assumed to be of less importance. However, the porcine model used may not be completely representative of the clinical setting. Cerebral blood flow in pigs is somewhat lower than in humans $(8-10 ; 15)$. In addition, pigs also have a rete mirabile, which could affect the rate of embolization. This is a vascular rete situated between the carotidarteries and cerebral vessels, which acts a thermoregulator (16). These two factors may influence the rate of embolization in the model described here, and thus give levels lower than would have been found in humans.

This study corroborates previous findings that lipid micro-emboli from shed mediastinal blood causes massive microembolization in the brain(2;4). The question of the relation between these emboli and the cognitive dysfunction seen after surgery is not addressed in this study. The connection between the two entities is intriguing and several authors have suggested such a relation $(5 ; 6 ; 17)$. Our study did, however, reveal differences between different regions of the brain. Low levels were found in the brainstem, for example, and the highest in the gray matter of the cerebrum. These differences are probably due to differences in blood flow in different regions, but differences in the capillary network could also play a part in the trapping of emboli. One interesting observation is that we found the highest levels 
in the gray matter, which is involved in cognitive functions of the brain (18). This finding will further spur the debate on the possible relation between LME and postoperative cognitive dysfunction. In all, our findings clearly show that LME are unevenly dispersed in different parts of the brain, and there is no evidence that any region is spared form embolization.

The levels of radioactivity found in the heart, small intestine and skeletal muscle were low. These finding could be anticipated, since blood flow through, for instance skeletal muscle, is significantly reduced during CPB $(9 ; 10)$. The low uptake in the heart could be explained by the fact that it was working at a low output. This will lower the metabolism in the heart and reduce the blood flow in the coronary artery.

The radioactivity found in the lungs was higher than we had expected. Since the lung circulation is situated after the capillary bed in the systemic circulation, the high uptake in the lungs suggests recirculation of LME.

By using a radioactive method employing beta radiation to study these emboli, we found a model with which to follow the differential distribution in detail and which gave reproducible results. However, this method is not without difficulties. Firstly, radioactive contamination of samples during and after experiments is an issue that must be taken into consideration when performing experiment. For instance, great caution must be taken not to inflict any contamination from samples with higher radioactivity to samples with lower radioactivity. Secondly, isotope must be prepared carefully. In the first animals, high variation from animal to animal was observed. This gave us the lesson to stir the isotope thoroughly before retransfusion. Thirdly, there is always background radiation which will affect the results. However, with a high dose of radioactivity and software that excludes the background 
radiation, the impact of background radiation was negligible in this study. Finally, different tissues have different counting efficacies at scintillation counting (7). However, the examined organs were all in the same range, and therefore levels are comparable. In conclusion, the presented porcine model used here with radioactive triolein seems to be a reliable method for tracking lipid emboli and determining the differential distribution throughout the body.

This study clearly shows that lipid micro-embolization from shed mediastinal blood is not a phenomenon limited to the brain, but seems to affect every organ in the body. We did not study any potential effects the lipid emboli may have on different target organs. A high concentration of LME was found in the kidneys, which suggests that LME may play a role in the postoperative renal dysfunction seen after cardiac surgery with CPB. Our finding of lipid emboli in the brain was expected. However, the differences found in different regions was unexpected and may be helpful in the ongoing research on cognitive dysfunction after surgery.

In all, the study questions the plausibility of routinely retransfusing shed mediastinal blood containing lipid micro-emboli. Until evidence exists that these emboli are harmless, maybe it should be assumed that these emboli could be harmful, and care taken to avoid them. 


\section{Acknowledgements}

We wish to express our gratitude to Professor Bertil Persson and Gustaf Grafström at the Department of Radiation Physics, Lund University Hospital for helping us with the isotopes and Lars-Erik Nilsson at the Department of Clinical Physiology in Malmö, for providing us with technical assistance and software for scintillation counting. This study was founded by the Swedish Heart-Lung Foundation together with The Crafoord Foundation. 


\begin{tabular}{lcc}
\hline Brain - White matter & $0+/-0$ & $10188+/-9553$ \\
Brain - Gray matter & $0+/-0$ & $18356+/-14550$ \\
Brain - Brainstem & $0+/-0$ & $7054+/-6142$ \\
Brain - Hippocampus & $0+/-0$ & $11412+/-13034$ \\
Brain - Cerebellum & $0+/-0$ & $12777+/-10343$ \\
Heart & $0+/-0$ & $11107+/-11460$ \\
Lung & $0+/-0$ & $17117+/-24817$ \\
Liver & $0+/-0$ & $25614+/-18342$ \\
Kidney & $0+/-0$ & $176385+/-118563$ \\
Spleen & $0+/-0$ & $139565+/-138274$ \\
Small Intestine & $0+/-0$ & $17332+/-12910$ \\
Muscle & $0+/-0$ & $1980+/-1879$
\end{tabular}

Table 1. Levels of distribution of beta radiation in different organs expressed as disintegrations per minute per gram of tissue (DPM/g). Separate repeated-measurement ANOVA showed a significant difference within the different regions of the brain. 


\section{Figure legends}

Figure 1. A: Human shed blood containing triglycerides from the surgical field. B: Porcine blood with radioactive triglyceride added.

Figure 2. Relative distribution of radioactivity, measure as concentration of lipid micro emboli in different tissues, expressed as percent of total radioactivity from all tissues examined (values are standardized). 


\section{Figure 1}
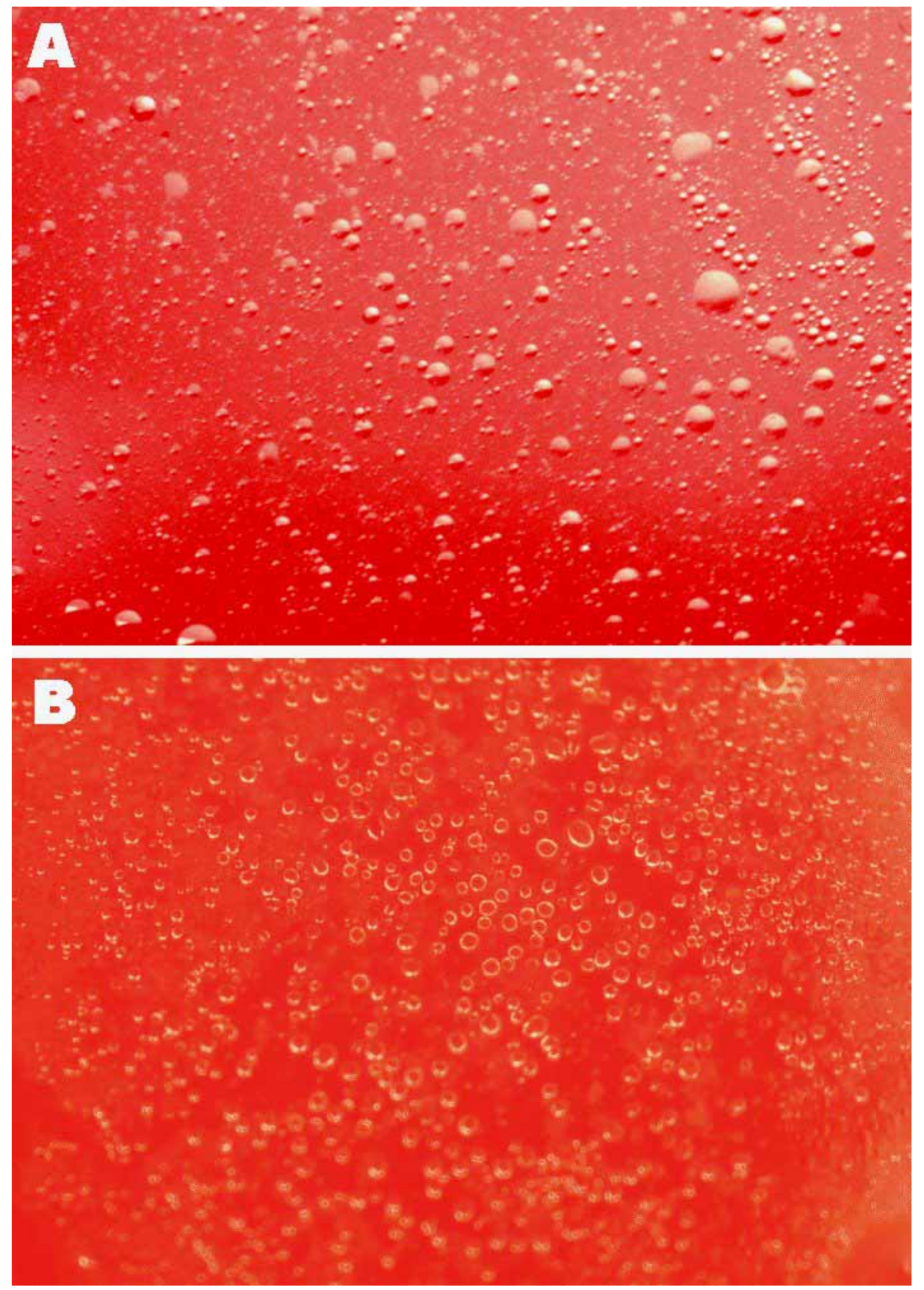
Figure 2

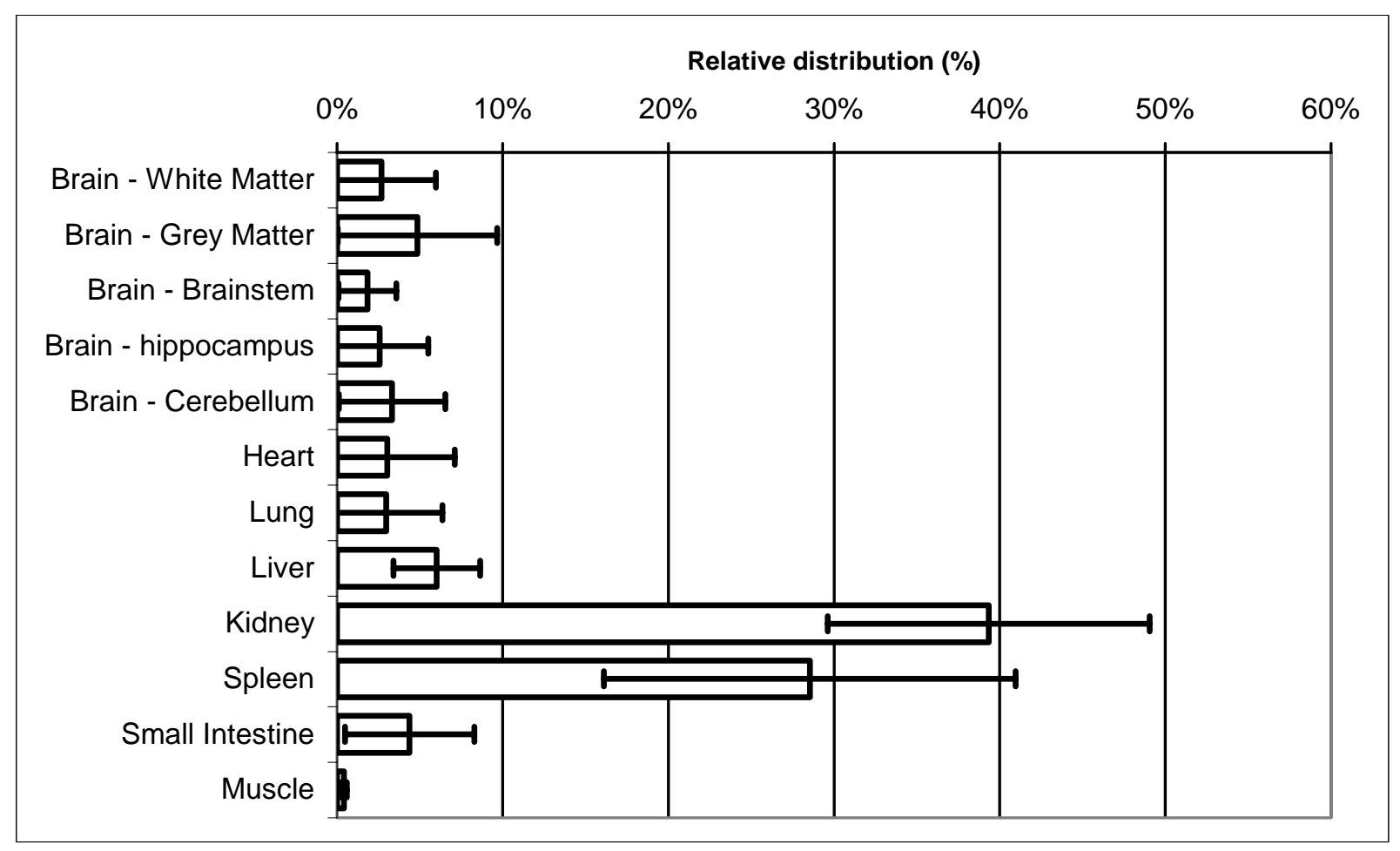




\section{Reference List}

(1) Brooker RF, Brown WR, Moody DM, Hammon JW, Jr., Reboussin DM, Deal DD et al. Cardiotomy suction: a major source of brain lipid emboli during cardiopulmonary bypass. Ann Thorac Surg 1998; 65(6):1651-1655.

(2) Brown WR, Moody DM, Challa VR. Cerebral fat embolism from cardiopulmonary bypass. J Neuropathol Exp Neurol 1999; 58(2):109-119.

(3) Moody DM, Bell MA, Challa VR, Johnston WE, Prough DS. Brain microemboli during cardiac surgery or aortography. Ann Neurol 1990; 28(4):477-486.

(4) Moody DM, Brown WR, Challa VR, Stump DA, Reboussin DM, Legault C. Brain microemboli associated with cardiopulmonary bypass: a histologic and magnetic resonance imaging study. Ann Thorac Surg 1995; 59(5):1304-1307.

(5) Taggart DP, Westaby S. Neurological and cognitive disorders after coronary artery bypass grafting. Curr Opin Cardiol 2001; 16(5):271-276.

(6) de Vries AJ, Gu YJ, Douglas YL, Post WJ, Lip H, van Oeveren W. Clinical evaluation of a new fat removal filter during cardiac surgery. Eur J Cardiothorac Surg 2004; 25(2):261-266.

(7) Kobayashi, Y. and Maudsley, D.V. 1974. In: Biological Applications of Liquid Scintillation Counting. Academic Press. pp 153-167.

(8) Selwyn AP, Shea MJ, Foale R, Deanfield JE, Wilson R, de Landsheere CM et al. Regional myocardial and organ blood flow after myocardial infarction: application of the microsphere principle in man. Circulation 1986; 73(3):433-443. 
(9) Boston US, Slater JM, Orszulak TA, Cook DJ. Hierarchy of regional oxygen delivery during cardiopulmonary bypass. Ann Thorac Surg 2001; 71(1):260-264.

(10) Slater JM, Orszulak TA, Cook DJ. Distribution and hierarchy of regional blood flow during hypothermic cardiopulmonary bypass. Ann Thorac Surg 2001; 72(2):542-547.

(11) Mangano CM, Diamondstone LS, Ramsay JG, Aggarwal A, Herskowitz A, Mangano DT. Renal dysfunction after myocardial revascularization: risk factors, adverse outcomes, and hospital resource utilization. The Multicenter Study of Perioperative Ischemia Research Group. Ann Intern Med 1998; 128(3):194-203.

(12) Appelblad M, Engstrom G. Fat contamination of pericardial suction blood and its influence on in vitro capillary-pore flow properties in patients undergoing routine coronary artery bypass grafting. J Thorac Cardiovasc Surg 2002; 124(2):377-386.

(13) Julien M, Hoeffel JM, Flick MR. Oleic acid lung injury in sheep. J Appl Physiol 1986; 60(2):433-440.

(14) Kim HJ, Lee JH, Lee CH, Lee SH, Moon TY, Cho BM et al. Experimental cerebral fat embolism: embolic effects of triolein and oleic acid depicted by MR imaging and electron microscopy. AJNR Am J Neuroradiol 2002; 23(9):1516-1523.

(15) Floyd TF, McGarvey M, Ochroch EA, Cheung AT, Augoustides JA, Bavaria JE et al. Perioperative changes in cerebral blood flow after cardiac surgery: influence of anemia and aging. Ann Thorac Surg 2003; 76(6):2037-2042.

(16) Burbridge B, Matte G, Remedios A. Complex intracranial arterial anatomy in swine is unsuitable for cerebral infarction projects. Can Assoc Radiol J 2004; 55(5):326-329. 
(17) Stump DA, Kon NA, Rogers AT, Hammon JW. Emboli and Neuropsychological Outcome Following Cardiopulmonary Bypass. Echocardiography 1996; 13(5):555558.

(18) Kolb and R.Tees. The decorticate rat. Whishaw IQ, editor. Cambridge, MA: M.I.T. Press, 1989). The neocortex of the Rat . 2005.

Ref Type: Generic 